\title{
Development of Learning Media "Solar System" Multiplayer Virtual Reality Using Samsung Gear VR
}

\author{
Muhammad Rifqi Mukhtar, Surya Sumpeno, and Supeno Mardi Susiki Nugroho \\ Computer Engineering Department, Faculty of Electrical Engineering \\ Institut Teknologi Sepuluh Nopember \\ E-mail: mukhtarrifqi@gmail.com
}

\begin{abstract}
The lack of student participation in the learning process results in the decrease of their learning interest and comprehension. In addition, in the interactive learning process, two-way communication takes place between instructors and learners. Teachers deliver learning material and learners provide responses to the learning material they receive. This can be realized by using a Multiplayer Virtual Reality to display the visualization of learning material. Virtual reality can be used to increase the effectiveness of delivering material with an immersive environment so students can develop intuition to perceive the abstract knowledge that is difficult for teachers to describe. The multiplayer system allows teacher-student interaction, which supports the ongoing learning activities in the virtual world. The test results show the mechanism of object interaction in a virtual environment is easy to use with $50 \%$ of respondents agreeing and $50 \%$ of respondents saying the interaction feels natural. Furthermore, solar system multiplayer virtual reality can be an interesting learning media with $50 \%$ of respondents strongly agree and this learning media is effective to be used in the delivery of solar and eclipse material in sixthgrade of elementary school with $67 \%$ of respondents expressing their agreement strongly.
\end{abstract}

Keywords-Virtual Reality, Multiplayer, Android, Samsung Gear VR, Education.

\section{INTRODUCTION}

$\mathrm{S}^{\mathrm{s}}$ TUDENT participation during the learning process tends to only consists of taking notes and listening to the teacher's explanation, students are very rarely to ask questions or argue, and even incline towards being quiet. As a result, the interaction between teachers and students only takes place in one direction which causes the learning atmosphere becomes dull. This condition becomes the factor behind the weariness in learning which students experience and this causes their learning activity in grasping the material remains low and adversely affects their comprehension of the learning material. [1]

It is also known that students need more attention in learning science. Science learning in elementary schools should be carried out in an interesting and fun way. Students of primary school age which are still in the concrete operational stage, require concrete examples in order to understand what they learn. Learning using conventional methods such as lectures is less suitable for science learning in elementary schools because many of the material objects are difficult to observe directly or not in the student's environment. Textbooks that guide students in learning science are also insufficient as a reference source because there are only pictures and illustrations.[2]
In the interactive learning process, two-way communication takes place between the instructor and the learner. Teachers deliver learning material and learners provide responses to the learning material they receive. In interactive learning, lecturers do not only act as deliverers of material but also receive feedback from students and provide reinforcement of the learning outcomes they have taken. [3] That is why the right learning media are needed to increase interaction, interest in learning and understanding of students. The right media in accordance with the objectives will be able to improve the learning experience and support learning outcomes.

This can be realized by an interesting and interactive learning media of a Multiplayer Virtual Reality using Samsung Gear VR Head-mounted Display to display the visualization of learning material and remote control to interact with the objects presented. Virtual reality can be used to increase the effectiveness of delivering material with an immersive environment so that students can develop intuition to perceive abstract knowledge that is difficult for teachers to describe. [4] The multiplayer system allows the teacher and student interaction, which supports the ongoing learning activities in the virtual world. In addition, the multiplayer system keeps the teacher in control of the material and can equate the experience and perception of all students towards the content of the lesson. Students are expected to get more understanding because their learning activities will not only consist of listening to the teacher's description, but also other activities such as observing, doing, and interacting directly with 3D objects in real-time. With the existence of this learning media, it is hoped that it can facilitate students to think and analyze, provide variations in learning, and students can understand the subject matter systematically.

\section{LITERATURE REVIEW}

\section{A. Learning Media}

Learning media are all things related to software and hardware that can be used to convey the contents of teaching material from learning sources to students (individuals or groups), which can stimulate the learner's thoughts, feelings, attention, and interests in such a way that the learning process (inside / outside the classroom) becomes more effective. [3]

\section{B. Virtual Reality}

There are four important elements in virtual reality. The four elements are as follows:

1. Virtual world, a content that creates a virtual world in the form of screenplay and script 
2. Immersion, a sensation that brings users of virtual reality technology to feel as if they are in a real environment which actually fictitious. Immersion is divided into 3 types, namely:

a) Mental immersion, making the users' mental feel like they are in a real environment

b) Physical immersion, making the physical of the user feel the atmosphere around the environment created by the virtual reality

c) Mentally immersed, giving sensation to users to sink in a virtual reality-generated environment

3. Sensory feedback functions to convey information from the virtual world to the senses of its users. This element includes visual, audio (hearing) and touch

4. Interactivity is incharge of responding to the actions of users, so that users can interact directly in a fictitious or virtual world field.

\section{METHODOLOGY}

Methodology is a system of broad principles or rules from which specific methods or procedures may be derived to interpret or solve different problems within the scope of a particular discipline. There are six main step to design and implement the application system design so it can produce the main output. The six elements are as follows:

\section{A. Literary Research}

Collect the reference especially curriculum about the solar system materials for sixth-grade of elementary school students which later will be the fundamental information for learning inside gameplay.

\section{B. Making Game Design}

In this process the author design the Game Design Document that include the main aspects about the game such as the rules, scoring, visual design, and leveling.

\section{Collect the Assets}

Collect and make the assets that used in the game likes sound assets and 2D or 3D models. Assets collected from the Unity Assets Store or another resources.

\section{Making the VR Environment}

Process of making scene in Unity according to the storyboard that already made with arrange all of the 3D assets, text, music, and adding visual effect. Avatar also added to represents the presence of the teacher and the students in virtual world.

\section{E. Configure the Controller}

Adding the control function to the player such as pointer interaction, select, and grab object with processing the input value from controller device.

\section{F. Adding the Multiplayer}

Connecting one device to another so they can interact inside the virtual world. Implement object spawn and also player's movement synchronization using Photon Unity Networking.

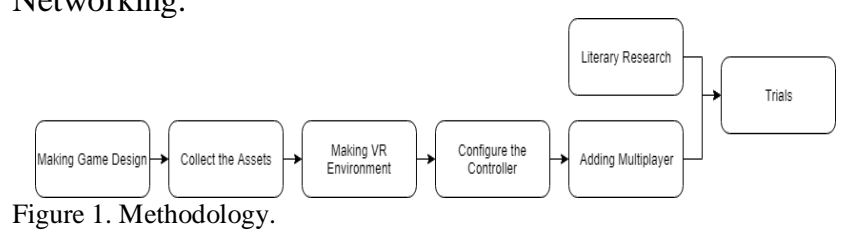

\section{SYSTEM DESIGN}

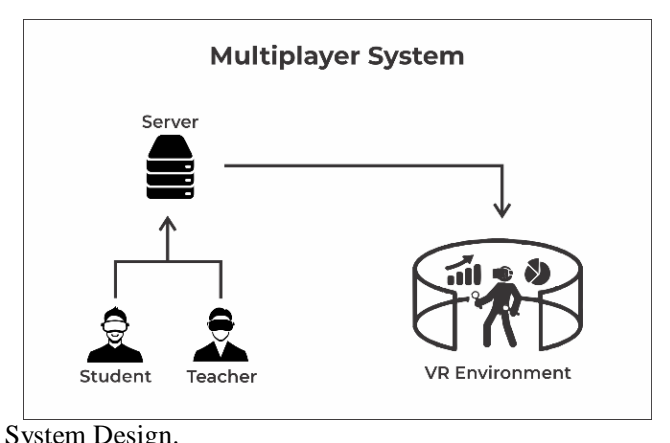

Figure 2. System Design.

This study aims to design a multiplayer-based learning media applications by utilizing a HMD device and device controller as an input and output device and a server to process data that can be used in multiplayer. Data input received will be displayed in the form of an avatar and interaction with virtual environments which will then be processed by the server so that it can be received and observed by all players. In order to realize this final project, a system design that describes the concept and work of the system is made.

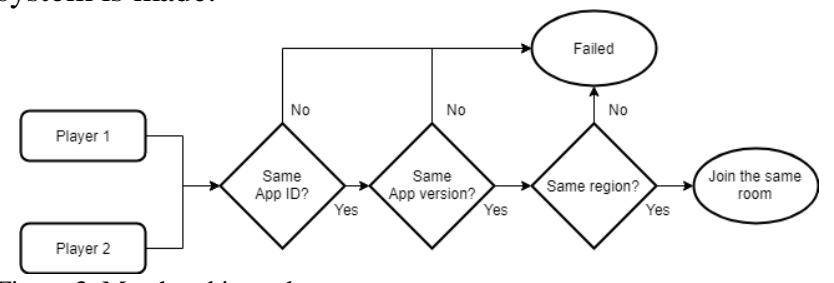

Figure 3. Matchmaking scheme.

\section{A. Storyboard Design}

\section{1) Mепu Display}

In this main menu, there are two choices of material that can be chosen by the user, the material of the solar system and eclipse material.

\section{2) Solar System Material}

In the material of the solar system, students will be confronted with spawner where later on this spawner will appear a planet randomly from the eight planets in the solar system. Students are asked to place the eight planets in the appropriate order, then observe the eight planets in the solar system revolving around the sun.

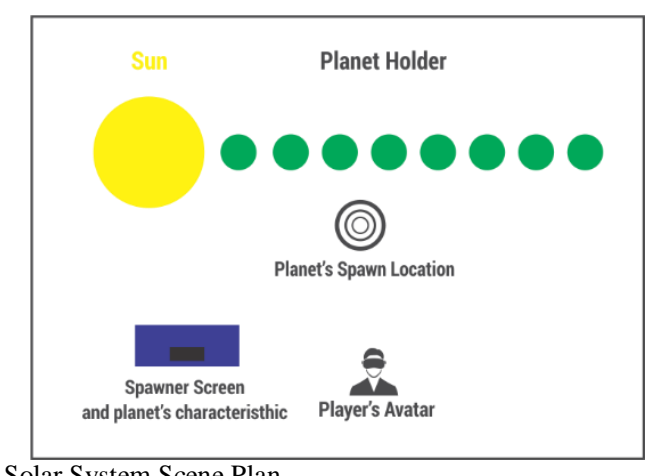

Figure 4. Solar System Scene Plan.

3) Eclipse Material

In the eclipse material menu, students are also faced with the object of the sun, earth, and moon. Then, students are asked to move the position of the moon into the right position such as when the solar eclipse or lunar eclipse occurs. If students can place the sun, earth and moon in the right position, students and teachers can observe the process of eclipse above them and as if they were observing an eclipse from the surface of the earth. 


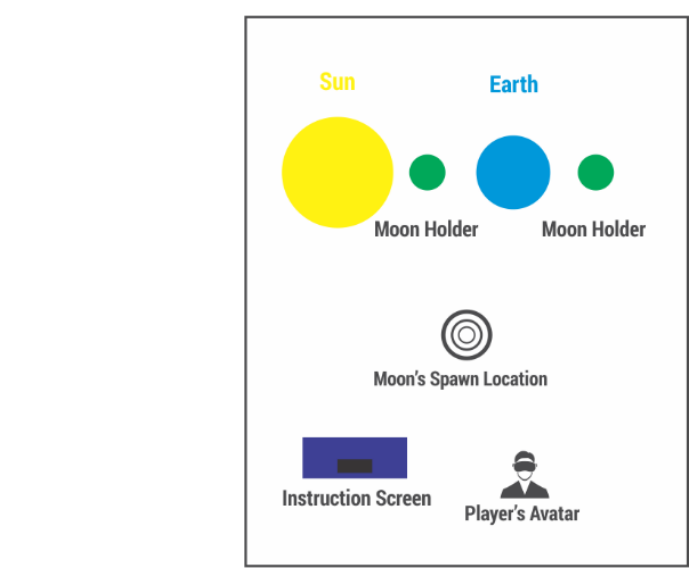

Figure 5. Eclipse Scene Plan.

\section{B. Student Worksheet}

A Student Worksheet is created to guide students to do various activities. It contains guidelines for the two materials in this application, the material of the solar system and eclipse material.

\section{1) Solar System Student Worksheets}

This Student Worksheet will be used as a guide to the solar system scenario with basic competency guidelines as shown in the following table 1 .

Table 1.

Basic competency for Solar System materials

\begin{tabular}{|c|c|c|}
\hline Standard Competency & Basic Competency & Indicator \\
\hline $\begin{array}{l}\text { Understanding the sun } \\
\text { as the center of the solar }\end{array}$ & $\begin{array}{l}\text { Describe the solar } \\
\text { system and the }\end{array}$ & $\begin{array}{l}\text { 1. Defines the notion } \\
\text { of the solar system }\end{array}$ \\
\hline $\begin{array}{l}\text { system and the } \\
\text { interaction of the earth } \\
\text { in the solar system. }\end{array}$ & $\begin{array}{l}\text { position of the solar } \\
\text { system. }\end{array}$ & $\begin{array}{l}\text { 2. Mention the } \\
\text { constituent } \\
\text { members of the } \\
\text { solar system. } \\
\text { 3. Mention the names } \\
\text { of planets in } \\
\text { sequence and their } \\
\text { size. } \\
\text { 4. Explain the rotation } \\
\text { of planets in the } \\
\text { solar system }\end{array}$ \\
\hline
\end{tabular}

In accordance with the basic curriculum above, a guideline is made as follows figure 6 .

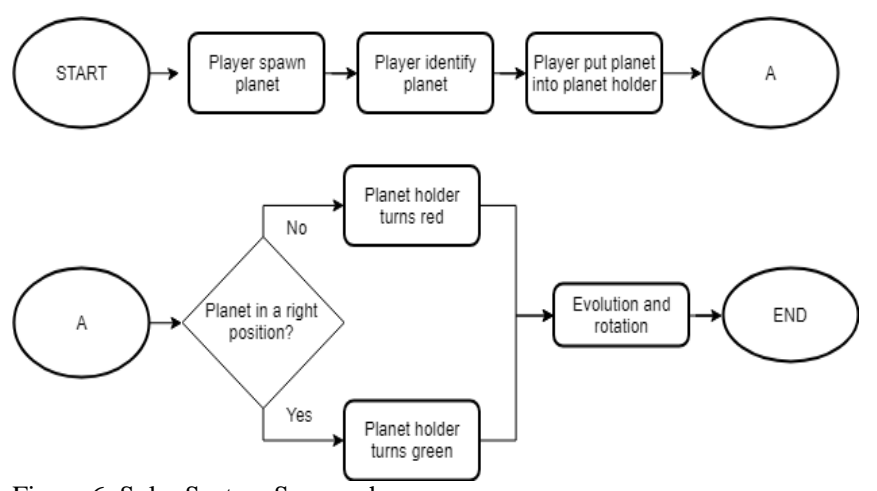

Figure 6. Solar System Scene scheme.

1. Students press the spawn button and planets will appear randomly

2. The teacher describes the characteristics of the planet

3. Students answer the name of the planet then put the planet in the order of its position.

4. Students observe the phenomenon that occurs with an explanation from the teacher.

\section{2) Eclipse Student Worksheet}

This Worksheet will be used as a guideline on eclipse scenarios with basic competency guidelines as shown in table 2.

Table 2 .

Basic competency for Eclipse materials

\begin{tabular}{|c|c|c|}
\hline Standard Competency & Basic Competency & Indicator \\
\hline $\begin{array}{l}\text { Understanding the sun } \\
\text { as the center of the solar } \\
\text { system and the } \\
\text { interaction of the earth } \\
\text { in the solar system. }\end{array}$ & $\begin{array}{l}\text { Explain the } \\
\text { occurrence of lunar } \\
\text { eclipses and solar } \\
\text { eclipses. }\end{array}$ & $\begin{array}{l}\text { 1. Explain the process } \\
\text { of lunar eclipses } \\
\text { and solar eclipses. } \\
\text { 2. Explain the total } \\
\text { lunar eclipse and } \\
\text { partial lunar } \\
\text { eclipse. } \\
\text { 3. Explain total solar } \\
\text { eclipses and partial } \\
\text { solar eclipsesproses } \\
\text { terjadinya gerhana } \\
\text { bulan dan gerhana } \\
\text { matahari. }\end{array}$ \\
\hline
\end{tabular}

In accordance with the basic curriculum above, a guideline is made as follows figure 7 .

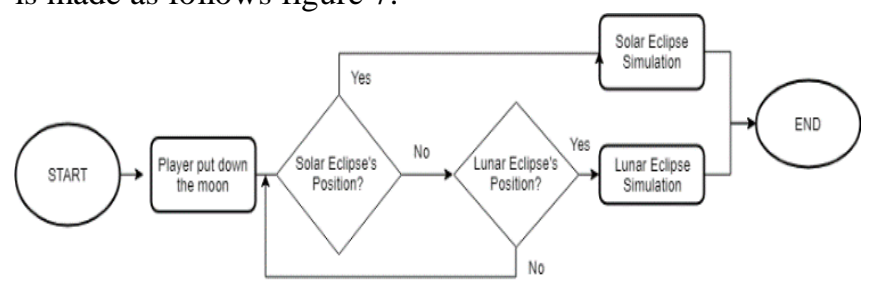

Figure 7. Eclipse Scene Scheme.

1. The teacher asks students to put the moon in a lunar eclipse position

2. Students are asked to observe the Sun, Earth, and Moon models then explain what happened.

3. Students observe shadows formed on the models of the Sun, Earth, and Moon.

4. Students observe the process of lunar eclipses in the sky.

5. Students exchange the position of the earth with the position of the moon then explain what events will occur.

6. Students observe shadows formed on the models of the Sun, Earth, and Moon.

7. Students observe the process of the solar eclipse in the sky.

\section{Controller Configuration}

In the Event System Unity, there is a Stand Alone Input Module component which is useful for following up data input from the mouse. In this application Virtual Reality Toolkit (VRTK) is used to get input values from the controller. With input from the controller, the player can, teleport, interact with 3D objects, and interact with the user interface. To interact using the Samsung gear VR controller, you can follow these steps:

1. Create an empty object with the name "RightController".

2. Add the VRTK Controller Event component.

3. Add the VRTK Pointer component and set the "activation button" to "Touchpad Press" and fill in the "Attach to" column with "RightHandAnchor" which is on OVRCameraRig.

4. Add the VRTK Straight Pointer Renderer component to add a pointer to the controller.

5. Activate "enable teleport" in the VRTK Pointer component in the RightController object.

6. Add the VRTKInteractGrab component and then set the "grab button" to "Trigger Press" and fill in the "Controllerattach point" column with "RightHandAnchor" located on OVRCameraRig. 
By using VRTK, after configuring the controller, several components can be added for interaction with the user interface:

1. Add the VRTK UI Pointer component to the RightController object.

2. Set the "activation button" to "Touchpad Press" and "selection button" to "Trigger Press".

3. Add VRTK UI Canvas and Raycaster Graphic components to the canvas object.

With this configuration, the UI Pointer will be active when the player presses the touchpad to enable teleportation when directed to an area that can be explored and will trigger UI elements such as buttons, sliders, and checkboxes using the trigger button when directed to the canvas object.

\section{Object Interaction}

The object must be able to detect the controller and need to be configured on what will happen if the grab button is pressed. With VRTK configuration objects can be done in the following ways:

1. Add collider components and rigid bodies to objects.

2. Add the VRTK Interactable Object component to the object.

3. Activate the "is Grabbable" option and Stay Grabbed on Teleport on the VRTK Interactable Object component.

4. Add the VRTK Track Object Grab Attach component to the object and fill in the Grab Attach Mechanic column in the VRTK Interactable Object with that component.

5. Fill in the Right Snap Handle column on the VRTK Track Object Grab Attach with the Transform component from the object itself.

This configuration allows objects to be able to detect the presence of a controller and can be grabbed by the player. By using the VRTK Track Object Grab Attach mechanic, Right Snap Handle on the object which in this case is the transform component of the object itself, will follow the value of the controller's transform so that the interaction feels natural.

\section{TESTING AND DISCUSSION}

There are two stages of testing, System Performance Testing, which includes testing the framerate in each scene with the device used and Usability Testing which consists of effectiveness testing and questionnaire testing.

\section{A. System Performance Testing}

In testing the performance of the system, the system is tested on both scenes in the application to determine system performance based on the obtained framerate. The devices used in performance testing are Samsung Galaxy Note 5 and Samsung Galaxy A8 + which have the following technical specifications.

Table 3.

Specifications for Samsung Galaxy Note 5

\begin{tabular}{l|l}
\hline \hline \multicolumn{2}{c}{ Samsung Galaxy Note 5 Specification } \\
\hline Processor & Octa-core $(4 \times 2.1 \mathrm{GHz}$ Cortex-A57 \\
& $\& 4 \times 1.5 \mathrm{GHz}$ Cortex-A53) \\
RAM & $4 \mathrm{~GB}$ \\
GPU & Mali-T760MP8 \\
HDD & $32 \mathrm{~GB}$ \\
Operation System & Android N 7.0 (Nougat) \\
\hline
\end{tabular}

\section{1) Framerate Testing}

Framerate is the replacing frequency of images displayed on the screen. The minimum framerate of an application to be comfortable to use is $30 \mathrm{FPS}$, and the recommended framerate is 60 FPS [5]. The framerate test is carried out in two scenes, the solar system simulation scene and eclipse simulation scene. The framerate test results from the application are as follows table 4 .

Table 4.

Specifications for Samsung Galaxy A8+

\begin{tabular}{|c|c|c|c|c|}
\hline \multicolumn{5}{|c|}{ Samsung Galaxy A8+ Specification } \\
\hline \multicolumn{2}{|c|}{ Processor } & \multicolumn{3}{|c|}{$\begin{array}{l}\text { Octa-core }(2 \times 2.2 \mathrm{GHz} \text { Cortex } \\
\& 6 \times 1.6 \mathrm{GHz} \text { Cortex-A53) }\end{array}$} \\
\hline \multicolumn{2}{|l|}{ RAM } & \multicolumn{3}{|c|}{$6 \mathrm{~GB}$} \\
\hline \multicolumn{2}{|l|}{ GPU } & \multicolumn{3}{|c|}{ Mali-G71 } \\
\hline \multicolumn{2}{|l|}{ HDD } & \multicolumn{3}{|c|}{$64 \mathrm{~GB}$} \\
\hline \multicolumn{2}{|c|}{ Operation System } & \multicolumn{3}{|c|}{ Android N 8.0 (Oreo) } \\
\hline \multicolumn{5}{|c|}{$\begin{array}{c}\text { Table } 5 . \\
\text { Samsung Galaxy Note } 5 \text { Framerate }\end{array}$} \\
\hline \multirow[t]{2}{*}{ No } & \multicolumn{4}{|c|}{ Solar System Scene } \\
\hline & \multicolumn{2}{|c|}{ Min } & Max & Mean \\
\hline 1 & \multicolumn{2}{|c|}{2.004057} & 51.74615 & 32.7612 \\
\hline 2 & \multicolumn{2}{|c|}{2.049182} & 47.61628 & 29.71036 \\
\hline 3 & \multicolumn{2}{|c|}{2.04542} & 47.54623 & 33.8075 \\
\hline 4 & \multicolumn{2}{|c|}{2.029641} & 44.54967 & 29.96256 \\
\hline 5 & \multicolumn{2}{|c|}{2.021838} & 41.02639 & 30.73237 \\
\hline & \multicolumn{4}{|c|}{$\begin{array}{c}\text { Table } 6 . \\
\text { Samsung Galaxy A8+ Framerate }\end{array}$} \\
\hline No & \multicolumn{4}{|c|}{ Solar System Scene } \\
\hline & $\mathrm{M}$ & & Max & Mean \\
\hline 1 & 17.4 & 343 & 46.4762 & 29.52125 \\
\hline 2 & 19.6 & 811 & 60.36008 & 40.95329 \\
\hline 3 & 19.4 & 365 & 48.36022 & 32.31986 \\
\hline 4 & 18.0 & 979 & 60.61546 & 37.50393 \\
\hline 5 & 20.4 & 755 & 56.64315 & 35.2943 \\
\hline
\end{tabular}

In Table 5-6 the results of these tests are shown and the average framerate obtained in each test ranges from the minimum framerate, which is 30 FPS. Thus users can comfortably explore in this scene.

Table 7.

Samsung Galaxy Note 5 Framerate

\begin{tabular}{llll}
\hline \hline \multirow{3}{*}{ No } & \multicolumn{3}{c}{ Eclipse Scene } \\
\cline { 2 - 4 } & Min & Max & Mean \\
\hline 1 & 11.26001 & 32.5229 & 18.18719 \\
2 & 12.88053 & 41.57805 & 23.12559 \\
3 & 14.20081 & 42.35335 & 22.37372 \\
4 & 12.68654 & 39.39499 & 22.16584 \\
5 & 13.39963 & 39.50207 & 23.27645 \\
\hline \hline \multicolumn{4}{c}{ Table 8. } \\
\multicolumn{4}{c}{ Eclipse Scene } \\
\hline \hline \multirow{4}{*}{ Samsung Galaxy A8+ Framerate } \\
\cline { 2 - 4 } & Min & \multicolumn{3}{c}{ Max } & Mean \\
\hline 1 & 0.465936 & 34.74028 & 19.82203 \\
2 & 1.089903 & 37.06665 & 23.1408 \\
3 & 15.1315 & 39.60955 & 24.05574 \\
4 & 11.95754 & 42.43775 & 25.78294 \\
5 & 14.64996 & 40.18592 & 21.34706 \\
\hline \hline
\end{tabular}

In Tables 7-8, the results of these tests are shown and the average framerate obtained at each test is less than the minimum framerate, 30 FPS. This is because when the solar eclipse simulation runs the exposure setting on the skybox is changed to darker to get the appropriate display. Moreover, the addition of the number of stellar particles in the simulation of the system particle which originally the max particle variable was 100 , now is increased to 600 . Both of these causes fps decrease in the solar eclipse scene because it requires heavy computing.

\section{B. Usability Testing}

Usability is the extent to which a product can be used by a particular user in achieving a goal with effectiveness, efficiency, and satisfaction in the specified context [6]. In this test two main scenes were prepared, the solar system scene, 
and the eclipse scene. In each scene there are several different tasks. The measured parameter is the time spent by participants in completing each task. In addition, questionnaire data were given to participants at the end of the experiment.

Table 9.

Participant's Task

\begin{tabular}{lll}
\hline \hline No & Task & Description \\
\hline 1 & $\begin{array}{l}\text { Spawn Planet } \\
2\end{array}$ & $\begin{array}{l}\text { Sequencing } \\
\text { Planets }\end{array}$ \\
3 & Placing the Moon & $\begin{array}{l}\text { Placing planets in the right order. } \\
\text { Placing the moon in a predetermined eclipse } \\
\text { scenario. }\end{array}$ \\
4 & $\begin{array}{l}\text { Observing } \\
\text { Eclipse }\end{array}$ & Observing the eclipse process. \\
\hline \hline
\end{tabular}

2) Effectiveness Testing

This effectiveness test can be done by taking into account the completion rate measurement by asking participants to complete a set of tasks that have been provided. In addition, participants will be timed to measure how long they take in completing tasks and simulations. The goal is to be able to measure how effectively the player can complete the task in the simulation.

Table 10 .

Completion Rate

\begin{tabular}{llll}
\multicolumn{4}{c}{ Completion Rate } \\
\hline \hline Task & Participant & Success & Completion Rate \\
\hline 1 & 15 & 13 & $87 \%$ \\
2 & 15 & 13 & $87 \%$ \\
3 & 15 & 14 & $93 \%$ \\
4 & 15 & 14 & $93 \%$ \\
\hline \hline
\end{tabular}

In the task of placing the planet, there are two failed attempts because the planetary object does not appear when called into the scene. Whereas in the task of placing the moon and observing the eclipse there was a failed experiment. In this experiment, the moon object disappeared from the scene so that the eclipse event cannot be triggered.

Table 11.

Solar System Completion Time

\begin{tabular}{llll}
\hline \hline \multirow{3}{*}{ Total Participant } & \multicolumn{3}{c}{ Solar System Completion Time } \\
& Fastest & Mean & Slowest \\
\hline 15 & $268 \mathrm{~s}$ & $493.2 \mathrm{~s}$ & $798 \mathrm{~s}$ \\
\hline \hline
\end{tabular}

Table 12.

Eclipse Completion Time

\begin{tabular}{clll}
\hline \hline Total & \multicolumn{3}{l}{ Eclipse Completion Time } \\
Participant & Fastest & Mean & Slowest \\
\hline 15 & $311 \mathrm{~s}$ & $366.8 \mathrm{~s}$ & $570 \mathrm{~s}$ \\
\hline \hline
\end{tabular}

Based on the results of completion time testing in tables 4.9 and 4.10 , it can be seen that there are some participants who need a longer time than the other participants, this is because in some experiments the controller devices connected to smartphones have improper orientation, making it difficult for participants to do the task. Another thing that affects the participants' time is an internet connection that is sometimes interrupted which caused participants to be disconnected from the room.

3) Questionnaire Testing

The testing of this questionnaire is done by giving questionnaires to participants who have tried the application. This test was conducted on 15 participants who were students of the Institut Teknologi Sepuluh Nopember aged 17-23 years. In testing this questionnaire, participants were given a number of statements and five options regarding the level of approval and are asked to choose one of these options. A list of statements can be seen below:

1. I can easily control the navigation / movement of player characters in the virtual environment.
2. The navigation / movement player control mechanism in the virtual environment feels natural.

3. I can easily control objects in the virtual environment.

4. The mechanism of interacting objects in a virtual environment feels natural.

5. I can control User Interface (buttons, menu options) easily.

6. The virtual environment feels responsive and there is no delay with the actions I take.

7. The sensation of exploration in the virtual world is interesting.

8. The description of the virtual environment is quite representative of real life.

9. The objects presented are quite representative and accurate with the real world.

10. I can complete the task of sorting planets easily.

11. I can complete the eclipse arranging task easily.

12. I am proficient in moving and interacting with the virtual environment.

13. The quality of the visual display does not interfere and does not distract me from doing the assigned task.

14. The control device (hardware) does not interfere with the assigned task performance.

15. Me and other players like being in the same environment.

16. I can communicate and interact with other players smoothly.

17. The objects presented can be well received by all players.

18. This learning media can improve my understanding of 6th grade elementary school solar material.

19. This learning media is quite effective and interesting for delivering solar and eclipse subject matter.

20. Compared to before the simulation, my understanding of the solar system, planets and eclipses increased.

Table 13.

Questionnaire

\begin{tabular}{rrrrrr}
\hline \multirow{5}{*}{ No } & \multicolumn{5}{c}{ Scale } \\
\cline { 2 - 6 } & $\begin{array}{c}\text { Strongly } \\
\text { Disagree (1) }\end{array}$ & $\begin{array}{c}\text { Disagree } \\
(2)\end{array}$ & $\begin{array}{c}\text { Neutral } \\
(3)\end{array}$ & $\begin{array}{c}\text { Agree } \\
(4)\end{array}$ & $\begin{array}{c}\text { Strongly } \\
\text { Agree (5) }\end{array}$ \\
\hline 1 & $0 \%$ & $13 \%$ & $13 \%$ & $47 \%$ & $27 \%$ \\
2 & $0 \%$ & $20 \%$ & $20 \%$ & $53 \%$ & $7 \%$ \\
3 & $0 \%$ & $13 \%$ & $20 \%$ & $60 \%$ & $7 \%$ \\
4 & $0 \%$ & $0 \%$ & $27 \%$ & $53 \%$ & $20 \%$ \\
5 & $0 \%$ & $7 \%$ & $27 \%$ & $40 \%$ & $27 \%$ \\
6 & $0 \%$ & $0 \%$ & $20 \%$ & $60 \%$ & $20 \%$ \\
7 & $0 \%$ & $0 \%$ & $7 \%$ & $33 \%$ & $60 \%$ \\
8 & $0 \%$ & $0 \%$ & $20 \%$ & $33 \%$ & $47 \%$ \\
9 & $0 \%$ & $0 \%$ & $7 \%$ & $53 \%$ & $40 \%$ \\
10 & $0 \%$ & $13 \%$ & $7 \%$ & $53 \%$ & $27 \%$ \\
11 & $0 \%$ & $7 \%$ & $13 \%$ & $33 \%$ & $47 \%$ \\
12 & $0 \%$ & $13 \%$ & $20 \%$ & $40 \%$ & $27 \%$ \\
13 & $0 \%$ & $0 \%$ & $0 \%$ & $67 \%$ & $33 \%$ \\
14 & $0 \%$ & $7 \%$ & $20 \%$ & $40 \%$ & $33 \%$ \\
15 & $0 \%$ & $0 \%$ & $7 \%$ & $40 \%$ & $53 \%$ \\
16 & $0 \%$ & $0 \%$ & $33 \%$ & $47 \%$ & $20 \%$ \\
17 & $0 \%$ & $13 \%$ & $7 \%$ & $47 \%$ & $33 \%$ \\
18 & $0 \%$ & $0 \%$ & $7 \%$ & $40 \%$ & $53 \%$ \\
19 & $0 \%$ & $0 \%$ & $0 \%$ & $33 \%$ & $67 \%$ \\
20 & $0 \%$ & $0 \%$ & $0 \%$ & $60 \%$ & $40 \%$ \\
\hline \hline
\end{tabular}

Statements number 1 to 5 are intended to know how the user experience the control system, interaction and navigation in the virtual world. Statements number 6 to 14 are intended to measure the user's comfort towards the virtual environment and the user's control over the tasks assigned. Statements number 15 to 17 are intended to determine the extent to which the multiplayer functions in this application can work well. Statements number 18 to 10 are to measure the function of this application as a learning media for the solar system and 
eclipse. The following are the results of testing the questionnaire.

\section{CONCLUSION}

The application can be used with a convenient framerate even though during the solar eclipse simulation the framerate can drop up to below $30 \mathrm{fps}$.

In questionnaire testing, the mechanism of object interaction in a virtual environment is easy to use with $50 \%$ of respondents agreeing and $50 \%$ of respondents saying the interaction feels natural.

Solar System Multiplayer Virtual Reality can be an interesting learning media with $50 \%$ of respondents strongly agree and this learning media is effective to be used in the delivery of solar and eclipse material in sixth-grade of elementary school with $67 \%$ of respondents agreeing strongly.

\section{REFERENCES}

[1] N. J. and A. Ambiyar, Media dan sumber pembelajaran. Jakarta: Kencana, 2016.

[2] E. Ihzandy, "Pengembangan multimedia pembelajaran:"sistem tata surya" berbasis flash pada mata pelajaran ilmu pengetahuan alam kelas VI SDN 2 tanggulanom selopampang, temanggung, jawa tengah," Universitas Negeri Yogyakarta, 2016.

[3] S. Hujair AH, Media pembelajaran interaktif inovatif. Kaukaba, 2013.

[4] L. Ying, Z. Jiong, S. Wei, W. Jingchun, and G. Xiaopeng, "Vrex: virtual reality education expansion could help to improve the class experience (vrex platform and community for vr based education)." p. 1, 2017

[5] ios and tvos, "Frame rate.".

[6] K. C. H. Al-Kilidar and B. Kitchenham, "The use and usefulness of the iso/iec 9126 quality standard." 2005. 